\title{
Upregulation of Pleiotrophin Gene Expression in Developing Microvasculature, Macrophages, and Astrocytes after Acute Ischemic Brain Injury
}

\author{
Hsiu-Jeng Yeh, ${ }^{1}$ Yong Y. He, ${ }^{2}$ Jan Xu, ${ }^{2}$ Chung Y. Hsu, ${ }^{2}$ and Thomas F. Deuel ${ }^{1}$ \\ ${ }^{1}$ Department of Medicine, Division of Growth Regulation, Beth Israel Deaconess Medical Center, Boston, Massachusetts \\ 02215, and 2Department of Neurology, Washington University School of Medicine, St. Louis, Missouri 63310
}

Pleiotrophin (PTN) is a heparin-binding, $18 \mathrm{kDa}$ secretory protein that functions to induce mitogenesis, angiogenesis, differentiation, and transformation in vitro. PTN gene (Ptn) expression is highly regulated during development and is highest at sites in which mitogenesis, angiogenesis, and differentiation are active. In striking contrast, with the exception of the neuron, the Ptn gene is only minimally expressed in adults. We now demonstrate that Ptn gene expression is strikingly upregulated within $3 \mathrm{~d}$ in $\mathrm{OX}_{42}$-positive macrophages, astrocytes, and endothelial cells in areas of developing neovasculature after focal cerebral ischemia in adult rat. Ptn gene expression remains upregulated in these same cells and sites 7 and $14 \mathrm{~d}$ after ischemic injury. However, expression of the Ptn gene is signif- icantly decreased in cortical neurons 6 and $24 \mathrm{hr}$ after injury and is undetectable in degenerating neurons at day 3 . Neurons in contralateral cortex continue to express Ptn in levels equal to control, uninjured brain. It is suggested that PTN may have a vital role in neovascular formation in postischemic brain and that postischemic brain is an important model in which to analyze sequential gene expression in developing neovasculature. In contrast, Ptn gene expression in injured neurons destined not to recover is strikingly reduced, and potentially its absence may contribute to the failure of the neuron to survive.

Key words: pleiotrophin gene expression; ischemia; neovasculature; macrophage; astrocytes
Trophic factors are required for growth, differentiation, and maintenance of viability during development and after injury. Pleiotrophin (PTN) is a member of a newly identified family of developmentally regulated, secreted heparin-binding proteins (Milner et. al., 1989; Rauvala, 1989; Li et al., 1990); it is an 18 kDa protein that stimulates mitogenesis, angiogenesis, and neurite and glial process outgrowth guidance activities in vitro. In vivo, $P$ tn gene expression peaks during late embryogenesis and in perinatal growth. Because these are times of active proliferation and differentiation in both mesenchyme and the nervous system, it has been suggested that PTN signals these functions during development as well (Li et al., 1990; Raulo et al., 1992; Wanaka et al., 1993; Matsumoto et al., 1994; Rauvala et al., 1994; SilosSantiago et al., 1996). In contrast, with the exception of subpopulations of neurons, levels of Ptn gene expression are very much lower in adult animals (Li et al., 1990; Garver et al., 1994; Kurtz et al., 1995; Nakagawara et al., 1995; Silos-Santiago et al., 1996), suggesting that activation of the Ptn gene may occur and activate PTN signaling in responsive cells important in new tissue formation during recovery from injury.

Cerebral ischemia and infarction lead to death of both neurons and glial elements. However, because recovery of brain function is frequently noted in patients with stroke even in the absence of neuronal regeneration, the postischemic expression of trophic

Received Dec. 30, 1997; revised Feb. 25, 1998; accepted March 4, 1998.

This work was supported in part by Office of Naval Research Grant N00014-951-0582, National Institute of Neurological Diseases and Stroke Grants NS25545, NS28995, and NS32636, and National Institutes of Health Grants HL31102, CA66029, and CA49712 (T.F.D.).

Correspondence should be addressed to Thomas F. Deuel, Department of Medicine, Division of Growth Regulation, Beth Israel Deaconess Medical Center, 330 Brookline Avenue, Boston, Massachusetts 02215.

Copyright (C) 1998 Society for Neuroscience $\quad 0270-6474 / 98 / 183699-09 \$ 05.00 / 0$ factors has been analyzed to identify which factors may be upregulated and to correlate the expression of these factors with tissue recovery. Different neurotrophins (Lindvall et al., 1992; Hsu et al., 1993) and basic fibroblast growth factor (Speliotes et al., 1996; Lin et al., 1997) are expressed after global or focal cerebral ischemia. Previously, the expression pattern of the Ptn gene was analyzed and found to be similar to a number of the neurotrophin genes (Li et al., 1990; Silos-Santiago et al., 1996). Remarkably, its expression is also significantly increased in neurons of the hippocampus, piriform cortex, and parietal cortex after chemically induced seizures (Wanaka et al., 1993), indicating its potential for activation in cells of the CNS. However, the significance of its increased expression levels in cortex after chemically induced seizures is unclear, and its expression after other forms of brain injury has not been studied. Because PTN stimulates proliferation of endothelial cells (Courty et al., 1991; Fang et al., 1992) and has been implicated in tumor angiogenesis (Chauhan et al., 1993; Czubayko et al., 1996; Choudhuri et al., 1997; Relf et al., 1997), the formation of new blood vessels with the increased vascular density frequently noted after cerebral ischemia (Lin et al., 1998) offered the potential to seek contribution of PTN to recovery of brain function after injury through its angiogenic properties. To seek evidence that PTN may contribute to tissue recovery, we have now examined its expression pattern after focal cerebral ischemia in rats.

\section{MATERIALS AND METHODS}

Focal ischemia model. Long-Evans male rats (body weight, 300-350 gm) were used in this study. Housing and anesthesia concurred with guidelines established by the Institutional Animal Welfare Committee, in accordance with the Public Health Services Guide for the Care and Use of Laboratory Animals, of the United States Department of Agriculture regulations, and the Guidelines of Panel on Euthanasia of the American 
Veterinary Association. Rats were allowed free access to water and rat chow until surgery. Rats were anesthetized with ketamine $(100 \mathrm{mg} / \mathrm{kg}$, i.p.) and xylazine ( $5 \mathrm{mg} / \mathrm{kg}$, i.m.). The left femoral artery was cannulated for monitoring arterial blood pressure and heart rate and for arterial blood gas analysis. Mean arterial pressure was maintained at $>80$, and blood gas was maintained at $\mathrm{pH} 7.4 \pm 0.1, \mathrm{~Pa}_{\mathrm{O}_{2}}>80$, and $\mathrm{Pa}_{\mathrm{CO}_{2}} 37 \pm 7$. The rectal temperature was monitored and maintained at $37.0^{2} \pm 0.5^{\circ} \mathrm{C}$ via an electronic temperature controller linked to a heating lamp. The right middle cerebral artery (MCA) was exposed as described previously using microsurgical techniques (Liu et al., 1989; He at al., 1993). Briefly, after a $2 \mathrm{~cm}$ vertical skin incision midway between the right eye and ear and splitting of the temporalis muscle, a $2 \mathrm{~mm}$ burr hole was drilled at the junction of the zygomatic arch and the squamous bone. The right MCA was ligated with a $10-0$ suture under an operating microscope. Complete interruption of blood flow at the MCA occlusion site was confirmed under the microscope. Both common carotid arteries (CCAs) that had been isolated previously and freed of soft tissues and nerves were then occluded using nontraumatic aneurysm clips. Temporary occlusion of the right MCA and both CCAs resulted in severe focal ischemia (reduction of blood flow by $88-92 \%$ ) confined to the cerebral cortex in the right MCA territory. Ischemia was mild (reduction of flow by $<20 \%$ ) in the right subcortical structures including the striatum and in the left hemisphere, which showed no morphological evidence of ischemic injury. The occlusion was removed at 90 min followed by reperfusion and at $6 \mathrm{hr}$ and $1,3,7$, and $14 \mathrm{~d}$ after occlusion. Ischemia for $90 \mathrm{~min}$ resulted in a persistent infarction in the right MCA cortex that was readily identified between $6 \mathrm{hr}$ and $7 \mathrm{~d}$ after ischemia (Lin et al., 1993). At the end of reperfusion, rats were killed after an overdose of sodium pentobarbital $(150 \mathrm{mg} / \mathrm{kg})$ followed by intracardiac perfusion with $200 \mathrm{ml}$ of $0.9 \%$ saline and $200 \mathrm{ml}$ of $4 \%$ paraformaldehyde. Fixed cerebrum was removed, and coronal sections were prepared.

Tissue fixation, embedding, and sectioning. After perfusion fixation, brains from each time point (three animals per group) and one brain from a sham-operated animal were post-fixed of 15 times the tissue volume of $10 \%$ neutral formalin, dehydrated through a series of ethanol baths, and embedded in paraffin, and serial sections of $5 \mu \mathrm{m}$ thickness were mounted on slides. Adjacent slides were used for comparison of in situ hybridization and immunohistochemistry.

Additional brains were removed and fixed in $4 \%$ paraformaldehyde overnight at $4^{\circ} \mathrm{C}$ and cryoprotected with $30 \%$ buffered sucrose. Another set of brains were prepared for frozen sections, which were used also for immunostaining.

In situ hybridization. The mouse Ptn cDNA (c clone; Li et al., 1990) was linearized and transcribed in vitro with ${ }^{35} \mathrm{~S}-\mathrm{UTP}(1250 \mathrm{Ci} / \mathrm{mmol}$; DuPont NEN, Boston, MA). Details of preparation of ${ }^{35} \mathrm{~S}-$ labeled Ptn RNA probes and conditions of hybridization were as described previously (Yeh et al., 1991). In control experiments, sections adjacent to those hybridized with the ${ }^{35} \mathrm{~S}$-labeled Ptn antisense RNA probe were treated as follows: (1) hybridization with a ${ }^{35} \mathrm{~S}$-labeled Ptn sense RNA probe, and (2) digestion with RNase A $(50 \mathrm{ng} / \mathrm{ml})$ for $1 \mathrm{hr}$ at $37^{\circ} \mathrm{C}$ before hybridization with ${ }^{35} \mathrm{~S}$-labeled $P$ tn antisense RNA probe to confirm the specificity of the ${ }^{35}$ S-labeled Ptn antisense RNA probe (data not shown).

Immunohistochemistry. Two types of anti-PTN antibody were used for immunoperoxidase staining. A monoclonal anti-PTN antibody was generated as described previously (Silos-Santiago et al., 1996). A chicken polyclonal anti-human PTN antibody was commercially prepared (Pocono Rabbit Farm and Laboratory, Canadensis, PA). Polyclonal antiGFAP antibodies (Sigma, St. Louis, MO) and monoclonal anti-OX $\mathrm{X}_{42}$ antibodies (mouse anti-rat CD11b/c equivalent; Harlan Sera Laboratories Ltd., Indianapolis, IN) were used for identification of astrocytes and macrophages, respectively. Endogenous peroxidase activity was blocked by treatment with $0.75 \% \mathrm{H}_{2} \mathrm{O}_{2}$ in PBS for $10 \mathrm{~min}$, and sections were incubated with $10 \%$ normal goat serum or $1 \%$ chicken serum from nonimmunized animals (in PBS) for $10 \mathrm{~min}$. The sections were subsequently incubated overnight at $4^{\circ} \mathrm{C}$ with anti-PTN antibody (1:100 dilution in 1\% BSA-PBS) or anti-GFAP antibody (1:50 dilution in 1\% BSA-PBS). The sections were then incubated with affinity-purified, biotinylated anti-mouse IgG (1:100 dilution; Life Technologies, Gaithersburg, MD), anti-chicken IgG (1:200 dilution; Sigma), or anti-rabbit IgG (1:100 dilution; Life Technologies), respectively, for $45 \mathrm{~min}$ followed by a $30 \mathrm{~min}$ incubation with streptavidin-horseradish peroxidase (1:100 dilution, Life Technologies). Finally, the sections were developed in DAB solution (Sigma)

Frozen sections were used to stain the macrophage using the monoclonal anti- $\mathrm{OX}_{42}$ antibody. The anti-OX $\mathrm{OX}_{42}$ antibody recognizes a common epitope shared by CD11b/c specific for macrophage (Robinson et al., 1986). Briefly, sections were pretreated with $1 \% \mathrm{H}_{2} \mathrm{O}_{2}$ in methanol for 30 min at $-20^{\circ} \mathrm{C}$ to block endogenous peroxidase, followed by $0.1 \%$ trypsin in $0.1 \% \mathrm{CaCl}_{2}$-PBS for $30 \mathrm{~min}$ at $37^{\circ} \mathrm{C}$ and blocking of nonspecific binding sites with $10 \%$ goat serum and $0.4 \%$ Triton $\mathrm{X}-100$ in PBS. Sections were then incubated with anti- $\mathrm{OX}_{42}$ (1:100 dilution in blocking solution) for $48 \mathrm{hr}$ at $4^{\circ} \mathrm{C}$, followed by the $\mathrm{ABC}$ procedure as described for immunostaining of PTN. Controls were performed in the adjacent sections to those reacted with antibodies by incubating sections with normal goat serum, rabbit serum, nonimmune chicken serum or $1 \%$ BSA-PBS in place of primary antibodies.

Histochemistry. The macrophage and microglial cells were also identified using D-galactosyl-specific $\mathrm{B}_{4}$ isolectin $\left(\mathrm{GSA}-\mathrm{IB}_{4}\right)$ conjugated with horseradish peroxidase followed by $\mathrm{DAB}$ in the presence of hydrogen peroxidase, according to methods described by Streit (1990) and Menon and Landerholm, (1994). The GSA-IB 4 derived from Griffonia simplicifolia seeds has been shown to stain selectively rat microglial cells in normal as well as pathologically altered brain (Streit and Kreutzberg, 1987). Sections adjacent to those immunostained with anti-PTN antibodies were incubated overnight at $4^{\circ} \mathrm{C}$ or for $2 \mathrm{hr}$ at room temperature with GSA-IB $_{4}(10 \mu \mathrm{g} / \mathrm{ml}$ in HBSS with $0.1 \%$ Triton $\mathrm{X}-100)$, followed by development in DAB, and counterstained with hematoxylin.

\section{RESULTS}

The pleiotrophin (Ptn) gene is predominantly expressed in cortical neurons in adult rat and mouse brain (Li et al., 1990; Wanaka et al., 1993; Silos-Santiago et al., 1996). In control sections from sham-operated brain and the left (contralateral to the ischemic lesion) hemisphere, the pattern of PTN expression was similar to that described previously (Wanaka et al., 1993; Silos-Santiago et al., 1996). Ptn mRNA and immunoreactivity of the PTN protein are readily seen in cortical neurons, but little or no expression of Ptn was observed in glia or the endothelial cells of the blood vessels in the normal brain or uninjured hemisphere (Fig. $1 A-C$ ). However, remarkable changes were demonstrated in the intensity and the regional distribution of $P$ tn gene expression in the right (injured) hemisphere. At $6 \mathrm{hr}$ and 1 and $7 \mathrm{~d}$ after reperfusion, expression of the Ptn gene in cortical neurons in the ischemic brain was drastically reduced. The decrease in Ptn gene expression was more rapid and to a greater degree in the ischemic core than in the peri-infarct region. Ptn mRNA signals were low in degenerating neurons in the outer layers of the infarct but not detectable in the ischemic core $6 \mathrm{hr}$ after induction of the lesion (Fig. 1D).

In contrast, transcripts of Ptn and PTN immunoreactivity were readily detected in glial cells in ischemic cortex, especially in the periphery of the infarct and the regions surrounding the injured area when examined 1-3 d after induction of the ischemic lesion (Figs. 2, 3A-C). Using an adjacent section immunostained with the anti-GFAP antibody, it was established that expression of the $P$ tn gene was localized to GFAP(+) astrocytes (Fig. 3D). The astrocytes were hypertrophic in appearance and exhibited strong GFAP(+) staining in the cell bodies and in the thick processes of these cells in the areas immediately adjacent to the border of injury area (Fig. 3D). At 1 and $3 \mathrm{~d}$ after ischemia, the astrocytes were increased in number in the white matter adjacent to the infarct (data not shown). In contrast, the contralateral side had little $\operatorname{GFAP}(+)$ staining in cortical astrocytes (data not shown). The morphology and distribution of the anti-PTNimmunostained cells bordering the injured area and peri-infarct region corresponded to that of GFAP $(+)$ astrocytes in the same area, suggesting that the $P$ tn and GFAP( + ) gene-expressing cells in sites immediately surrounding the ischemic lesion are astrocytes.

At day 3, transcripts of the Ptn gene were not seen in the area of the infarct. However, both transcripts and PTN protein were 

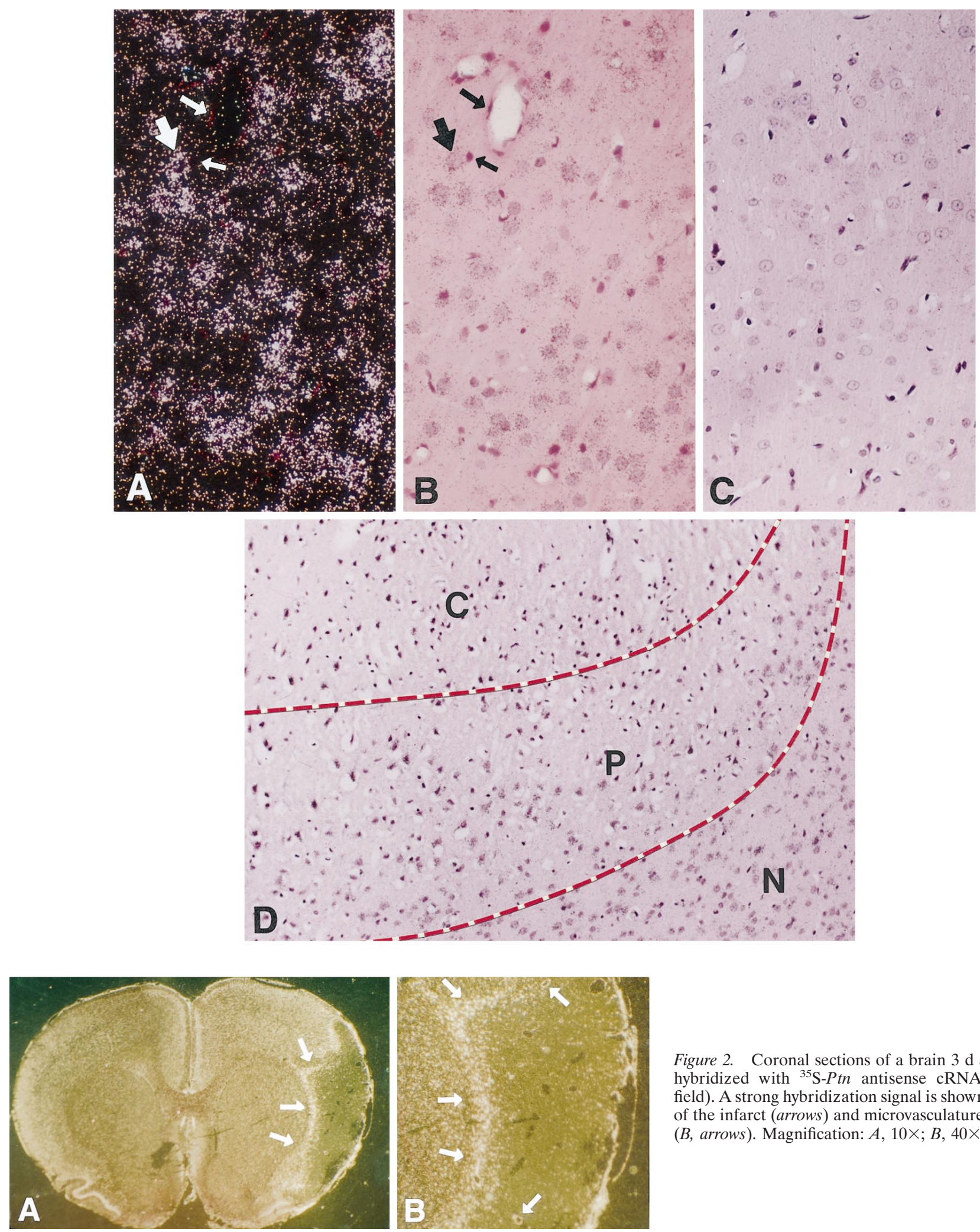

Figure 2. Coronal sections of a brain $3 \mathrm{~d}$ after ischemia hybridized with ${ }^{35} \mathrm{~S}-\mathrm{Ptn}$ antisense cRNA probe (dark field). A strong hybridization signal is shown at the border of the infarct (arrows) and microvasculature in the infarct (B, arrows). Magnification: $A, 10 \times ; B, 40 \times$.

Figure 1. Top. Sections of a brain from a sham-operated rat hybridized with ${ }^{35} \mathrm{~S}-\mathrm{Ptn}$ antisense cRNA probe $\left(A\right.$, dark field; $B$, bright field) or ${ }^{35} \mathrm{~S}-\mathrm{P} t \mathrm{tn}$ sense cRNA probe ( $C$, bright field). Ptn hybridization signal was highly expressed in neurons of cortex (large arrow). A little signal was found in glial cells (small arrow) and microvascular endothelium (medium arrow). $D$ (bright field), Section hybridized with ${ }^{35} \mathrm{~S}-\mathrm{PTN}$ antisense cRNA shows that PTN mRNA decreases to a greater degree in degenerating neurons in the ischemic core $(C)$ then in the periphery $(P)$ of the infarct compared with normal neurons (N) $6 \mathrm{hr}$ after reperfusions. Magnification: $A-C, 200 \times ; D, 100 \times$. 

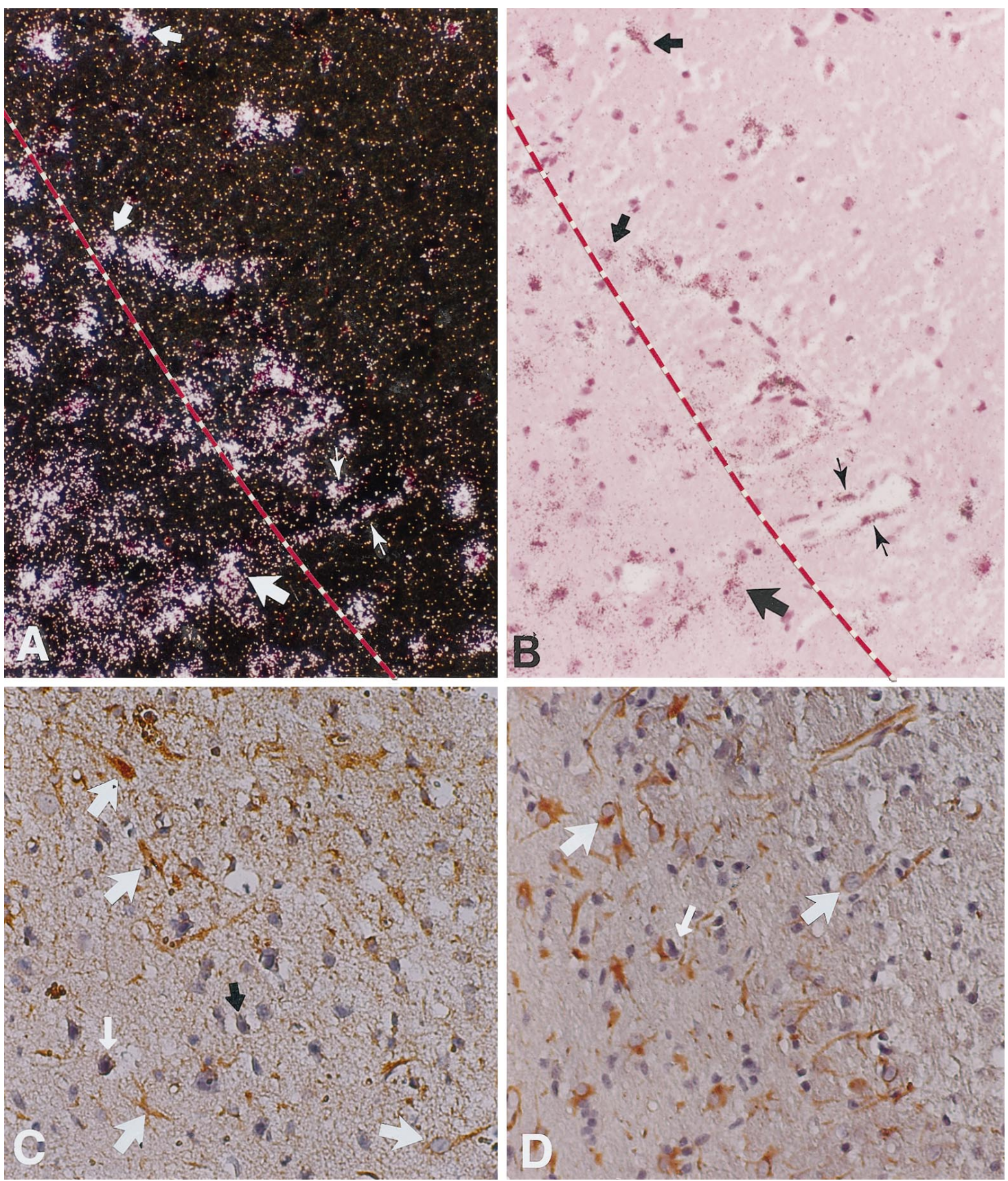

Figure 3. Sections of a brain $3 \mathrm{~d}$ after ischemia hybridized with ${ }^{35} \mathrm{~S}-\mathrm{Ptn}$ antisense cRNA $(A, B)$ and immunostaining with anti-PTN antibody $(C)$ or anti-GFAP antibody $(D)$. Ptn hybridization signal was predominantly expressed in the neurons (large arrow) and glial cells (small arrow) along the border of the infarct and blood vessels (arrowhead) immediately adjacent to the infarct (top right in $A$, dark field, $B$, bright field). PTN immunoreactivity was detected in glial cells (large arrow) at the border of the infarct $(C)$, which corresponded to the hypertrophic anti-GFAP $(+)$ astrocytes in the similar area on day 3 (D, large arrow); the small arrow denotes neurons under degeneration. Magnification, 200×.

expressed at striking levels in the microvasculature and macrophages (Figs. 4, 5, 6B). Virtually all of the cells that expressed detectable levels of $P$ tn transcripts were immunoreactive with anti-PTN antibodies as well. Of particular importance, a large number of macrophages were found near the vessels (Fig. 5) within the area of the infarct. These cells express high levels of $P$ tn mRNA (Fig. 6 $A, C$ ) and PTN immunoreactivity (Figs. 5A, $B$, $6 B$ ) but did not stain positively with anti-GFAP antibody (data not shown). The cells were confirmed as macrophages, because they were recognized by the anti-OX $\mathrm{X}_{42}$ antibody (Fig. $5 C$ ) and histochemical staining with $\mathrm{GSA}-\mathrm{IB}_{4}$ conjugated peroxidase (Figs. 5D, 6D, brown in cytoplasm).

Seven days after ischemia, the injured area consisted of large numbers of PTN-positive macrophages and hyperplastic blood vessels (Fig. 6B). The macrophages exhibited a wide range of morphological appearances, with round, oval, triangular, or square shapes and with the majority lacking identifiable processes. PTN immunoreactivity was readily identified in the cytoplasm of these macrophages and in the endothelial cells of the hyperplastic blood vessels (Fig. 6B). 

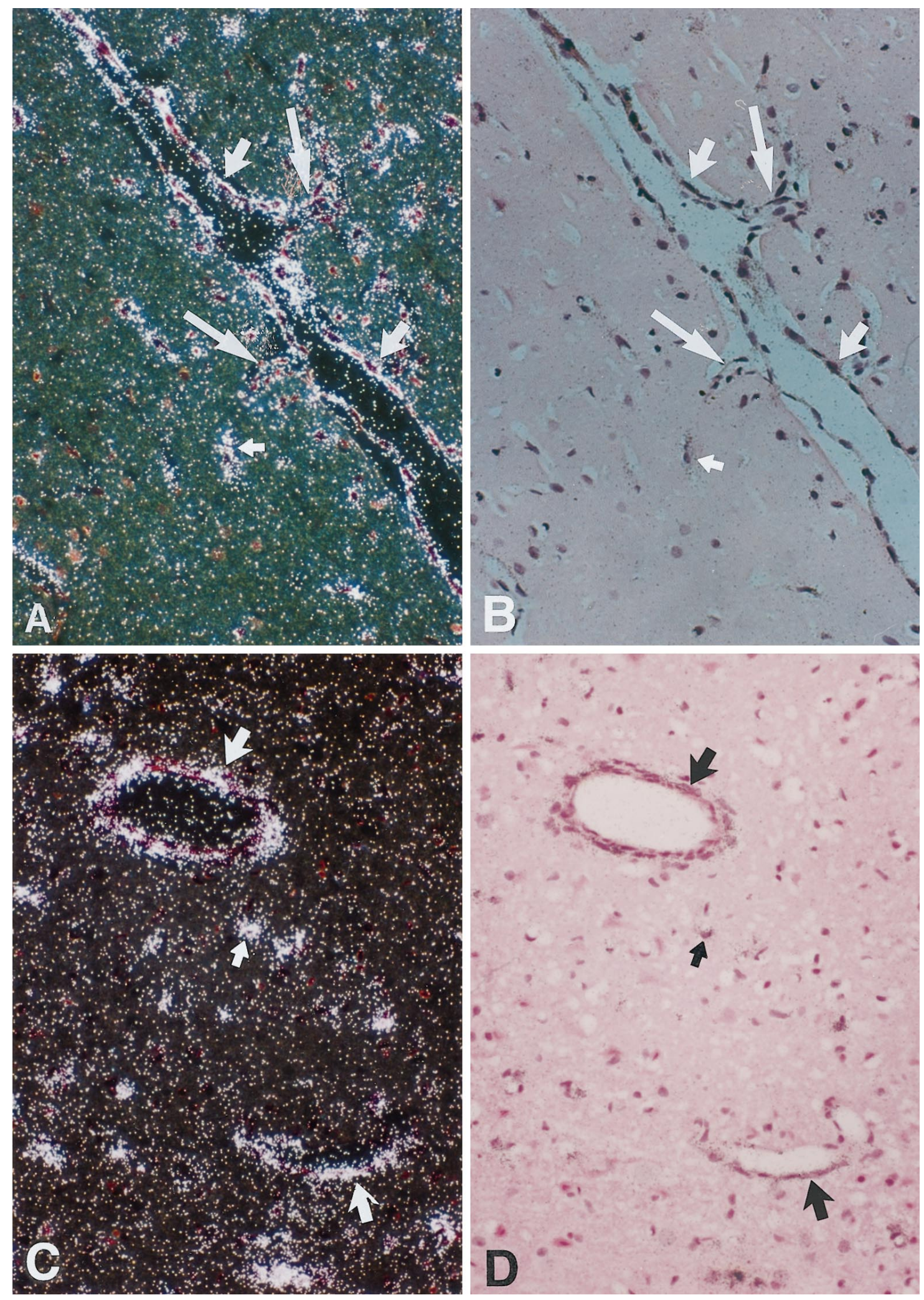

Figure 4. Sections of an ischemic brain on day 3 hybridized with ${ }^{35} \mathrm{~S}-P \operatorname{tn}$ antisense cRNA $(A$, $C$, dark field; $B, D$, bright field). PTN transcripts were found in the endothelium of blood vessels (large arrow) and glial cells (small arrow). Endothelial sprouts were seen in $A$ and $B$ (large arrow). Magnification, $200 \times$.

Fourteen days later, the infarct contained numerous macrophages with various morphological features (Fig. 6D), and residual necrotic tissue was usually surrounded by macrophages (Fig.
6C). GFAP $(+)$ astrocytes were no longer seen. There was very little PTN immunoreactivity in the microvascular endothelium or the cells surrounding the vessels. 

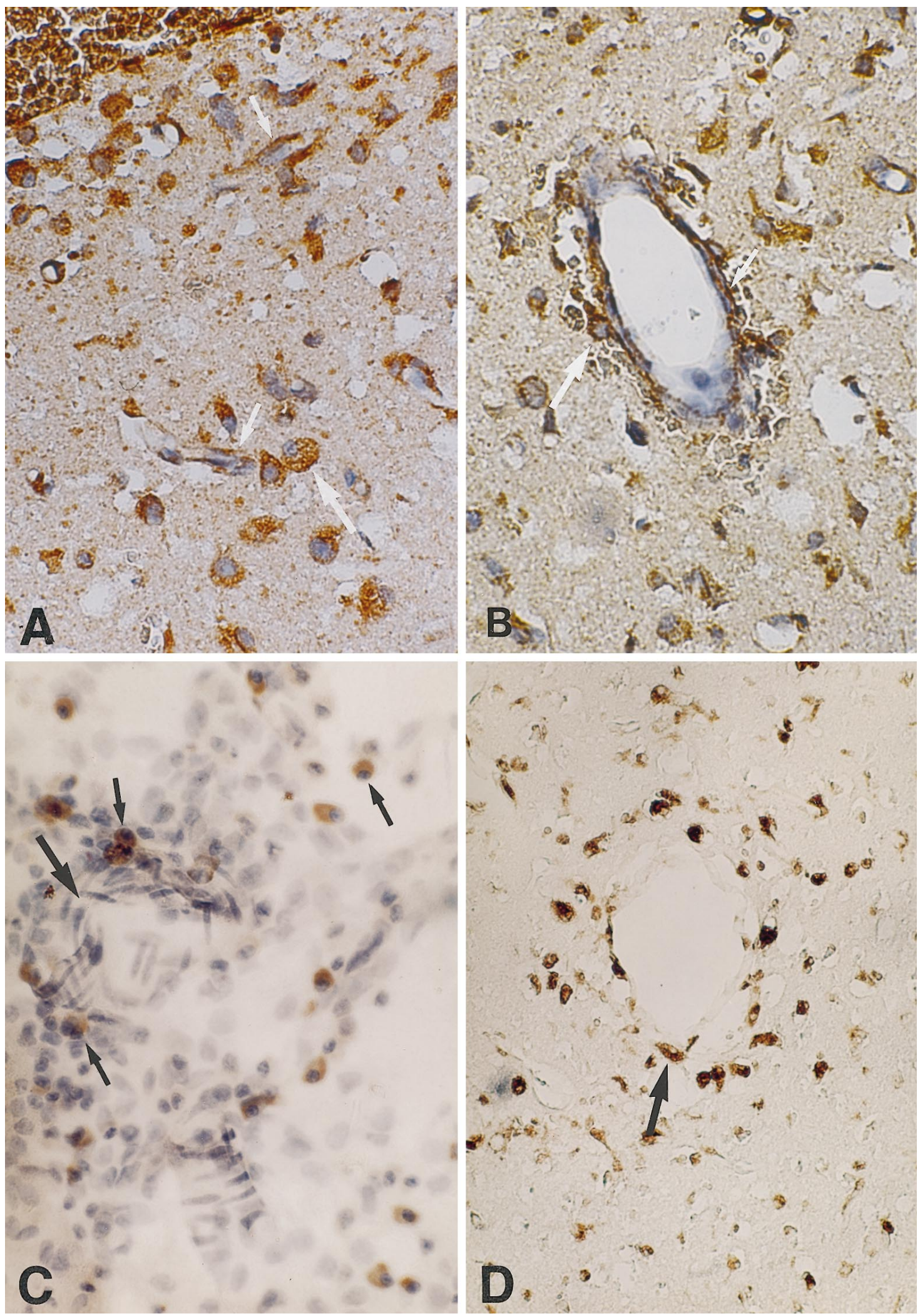

Figure 5. Sections of an ischemic brain on day 3. A, B, PTN immunoreactivity was found in endothelial cells (small arrow) and macrophages (large arrow) in the infarcted region after staining with anti-PTN antibody. $C, D$, Macrophages surrounding blood vessel (large arrow) were identified by immunostaining with anti-OX $\mathrm{OX}_{42}$ antibody $\left(C\right.$, arrow, frozen section) and histochemistry staining with GSA-IB ${ }_{4}(D$, arrow). Magnification: $A, B, 400 \times$; $C, D, 200 \times$. 



Figure 6. Sections of ischemic brain on days 3, 7, and 14. A, ${ }^{35}$ S-Ptn cRNA hybridization signals were detected in macrophages (arrow) near the infarcted area (top) on day 3 (bright field). $B$, A number of macrophages with PTN immunoreactivity (small arrow) with variable morphology in the infarcted area on day 7 (large arrow denotes a blood vessel). C, ${ }^{35}$ S-Ptn antisense cRNA hybridization signals were detected in numerous macrophages (arrow) surrounding residual necrotic tissue at the infarcted region on day 14 (bright field). $D$, A number of macrophages stained with GSA-IB ${ }_{4}$ with various morphological features in the infarct on day 14. Magnification: $A, B, 400 \times ; C, D, 100 \times$.

\section{DISCUSSION}

In this work, it is demonstrated that levels of the Ptn gene are differentially expressed in different cell types in ischemic rat brain. A very striking increase in the levels of expression of the $P t n$ gene was found in microglia and macrophages within areas of the exuberant neovasculature that formed at the margins of the infarct and in the endothelial cells of the newly formed vessels themselves. As described previously, a remarkable angiogenic response is seen after severe focal cerebral ischemia in this rat model (Lin et al., 1998). In the present study, it was observed that both the endothelial cells in neovasculature and the cells identified by the different specific macrophage and microglial markers that associate with the sites of angiogenesis exhibit intense Ptn mRNA signals, initially at $3 \mathrm{~d}$ and continuously through day 14 . Because PTN is a potent angiogenic agent in vitro, and tumors that derive from Ptn-transformed cells have striking new vessel formation (Chauhan et al., 1993), it is highly likely that PTN signaling is a very important contributor to the neovascularization in postischemic brain. It is also highly likely that the differential regulation of the Ptn gene in recovery from ischemic injury results from a specific set of "angiogenic" signals that are responsible for coordination of gene expression needed for the development of new blood vessels characteristic of ischemic injury. PDGF may be a candidate to initiate Ptn gene activation locally.
Ptn gene expression is increased by PDGF (Li et al., 1992a,b). PDGF is released by platelets, and the expression of PDGF-A is upregulated within $24 \mathrm{hr}$ in different cells at sites of injury. The neuron fails to express the PDGF- $\alpha$ receptor (Yeh et al., 1993). For this reason, it is possible that the neuron cannot respond to the same PDGF-A signal potentially responsible for upregulation of the Ptn gene in the context of ischemic brain injury.

During embryogenesis, Ptn mRNA is primarily expressed by progenitor cells in the subependymal layer of the brain in developing neuroepithelium and in the ependymal cells themselves, suggesting roles in cell division of both neural and vascular progenitors. During the perinatal stage, Ptn mRNA is seen in cells of neural as well as glial origins. In the adult brain, Ptn expression is restricted to selective neuronal subpopulations, including cerebral cortex (Li et al., 1990; Wanaka et al., 1993; Silos-Santiago et al., 1996). It is interesting to note that after ischemia, expression of Ptn in glia becomes evident again in the adult brain and is preferentially distributed in the regions surrounding the injured area. The identification of $P t n$ expression in astrocytes with GFAP immunoreactivity indicated that the injured brain reverts to a perinatal pattern of glial Ptn expression. Because $P$ tn is also expressed in the ependymal cells in embryogenesis and therefore is a potentially important contributor to early vasculogenesis in developing brain, its expression in neo- 
vascular endothelial cells may also reflect a reversion to the perinatal pattern of $P t n$ gene expression.

$P t h$ expression in cortical neurons is different; selected populations of cortical neurons continue to exhibit basal levels of Ptn gene expression in normal adult brain (Wanaka et al., 1993; Silos-Santiago et al., 1996). After severe focal ischemia leading to infarction, a striking loss of expression of the Ptn gene was observed in neurons that were irreversibly injured within the ischemic core. A substantial reduction was found in stressed or severely injured neurons at the periphery. Thus, in striking contrast to the glial elements, macrophages, and endothelial cells, $P$ tn gene expression is not activated in neurons. As noted above, it is likely that an important signal in recovery from ischemia brain injury is PDGF-A; the absence of the $\mathrm{PDGF}-\alpha$ receptor in neurons may therefore underlie the failure of neurons to express PTN in ischemic injury. The neurons in which $P$ tn gene expression is downregulated seem destined for cell death, in contrast to the neurons distant from the site of injury and neurons on the contralateral side that retain the high levels the Ptn mRNA signal intensity that is characteristic of uninjured neurons.

The significance of Ptn expression relative to the fate of neurons under ischemic insult is not clear. However, expression of selected genes may distinguish cell survival from cell death (States et al., 1996). Heat shock protein 70 (HSP70), a stress gene with putative cytoprotective action, is expressed only in neurons that survive ischemic insult but not in those neurons that sustain irreversible injury. Neurons dying of apoptosis can be separated from those that survive and express HSP70 by the absence of expression of this marker gene. Despite the neurotrophic properties of PTN, Ptn gene expression was not enhanced in injured neurons in the periphery of the ischemic core, suggesting that Ptn is not a stress gene for cortical neurons in the context of focal cerebral ischemia. In contrast, this failure of an increase in Ptn gene expression contrasts with increased Ptn expression and enhanced neuronal activity after chemical seizure (Wanaka et al., 1993), suggesting that perhaps $P$ tn gene expression contributes to selective maintenance of neuronal viability. Because the principle activities directed by PTN in neurons in culture are neurite outgrowth and perhaps axonal guidance (Rauvala et al., 1989, 1994; Li et al., 1990; Nolo et al., 1996), it is likely that the major role of PTN in neurons is related to differentiation and thus to promoting and maintaining the differentiated state of cortical neurons.

The present study demonstrates an altered pattern of Ptn expression affecting neuronal, glial, macrophage, and endothelial cell populations in the brain after focal cerebral ischemia-reperfusion. The fact that PTN protein was expressed in parallel with its mRNA signals supports the view that $P$ tn expression probably plays important pathophysiological roles in the restorative processes of the brain in response to ischemic injury and that neovascularization may be the principle role of PTN in this context.

\section{REFERENCES}

Chauhan AK, Li YS, Deuel TF (1993) Pleiotrophin transformations NIH 3T3 cells and induced tumors in nude mice. Proc Natl Acad Sci USA 90:679-682.

Choudhuri R, Zhang HT, Donnini S, Ziche M, Bicknell R (1997) An angiogenic role for the neurokines midkine and pleiotrophin in tumorigenesis. Cancer Res 57:1814-1819.

Courty J, Dauchel MC, Caruelle D, Perderiset M, Barritault D (1991) Mitogenic properties of a new endothelial cell growth factor related to pleiotrophin. Biochem Biophys Res Commun 180:145-151.

Czubayko F, Schulte AM, Berchem GJ, Wellstein A (1996) Melanoma angiogenesis and metastasis modulated by ribozyme targeting of the secreted growth factor pleiotrophin. Proc Natl Acad Sci USA 93:14753-14758.

Fang W, Hartmann N, Chow DT, Riegel AT, Wellstein A (1992) Pleiotrophin stimulates fibroblasts and endothelial and epithelial cells and is expressed in human cancer. J Biol Chem 267:25889-25897.

Garver Jr RI, Radford DM, Donis-Keller H, Wick MR, Milner PG (1994) Midkine and pleiotrophin expression in normal and malignant breast tissue. Cancer 74:1584-1590.

He YY, Hsu CY, Ezrin AM, Miller MS (1993) Polyethylene glycol conjugated superoxide dismutase in focal cerebral ischemiareperfusion. Am J Physiol 34:252-256.

Hsu CY, An G, Liu JS, Lin TN, Xue JJ, He YY (1993) Expression of immediate early gene and growth factor mRNAs in a focal cerebral ischemia model in the rat. Stroke 24:I78-I81.

Kurtz A, Schulte AM, Wellstein A (1995) Pleiotrophin and midkine in normal development and tumor biology. Crit Rev Oncog 6:151-177.

Li YS, Milner PG, Chauhan AK, Watson MA, Hoffman RM, Kodner CM, Milbrandt J, Deuel TF (1990) Cloning and expression of a developmentally regulated protein that induces mitogenic and neurite outgrowth activity. Science 250:1690-1694.

Li YS, Gurrieri M, Deuel TF (1992a) Pleiotrophin gene expression is highly restricted and is regulated by platelet-derived growth factor. Biochem Biophys Res Commun 184:427-432.

Li YS, Hoffman RM, LeBeau MM, Espinosa III R, Jenkins NA, Gilbert DJ, Copeland NG, Deuel TF (1992b) Characterization of the human pleiotrophin gene. J Biol Chem 267:26011-26016.

Lin TN, He YY, Wu G, M Kahn, Hsu CY (1993) Effect of edema on infarct volume in a focal cerebral ischemia model in the rat. Stroke 24:117-121.

Lin TN, Te J, Lee M, Sun GY, Hsu CY (1997) Induction of basic fibroblast factor (bFGF) expression following focal cerebral ischemia. Mol Brain Res 49:255-265.

Lindvall O, Ernfors P, Bengzon J, Kokaia Z, Smith ML, Seisjö BK, Persson H (1992) Differential regulation of mRNAs for nerve growth factor, brain-derived neurotrophic factor, and neurotrophin 3 in the adult rat brain following cerebral ischemia and hypoglycemic coma. Proc Natl Acad Sci USA 89:648-652.

Liu TH, Beckman JS, Freeman BS, Hogan EL, Hsu CY (1989) Polyethylene glycol-conjugated superoxide dismutase and catalase reduce ischemic brain injury. Am J Physiol 256:H589-H593.

Matsumoto K, Wanaka A, Takatsuji K, Muramatsu H, Muramatsu T, Tohyama M (1994) A novel family of heparin-binding growth factors, pleiotrophin and midkine, is expressed in the developing rat cerebral cortex. Brain Res Dev Brain Res 79:229-241.

Menon VK, Landerholm TE (1994) Intralesion injections of basic fibroblast growth factor alters glial reactivity to neural trauma. Exp Neurol 129:142-154.

Milner PG, Li YS, Hoffman RM, Kodner CM, Siegel NR, Deuel TF (1989) A novel $17 \mathrm{kD}$ heparin-binding growth factor (HBGF-8) in bovine uterus: purification and N-terminal amino acid sequence. Biochem Biophys Res Commun 165:1096-1103.

Nakagawara A, Milbrandt JD, Muramatsu T, Deuel TF, Zhao H, Cnaan A, Brodeur GM (1995) Differential expression of pleiotrophin and midkine in advanced neuroblastomas. Cancer Res 55:1792-1797.

Nolo R, Kaksonen M, Rauvala H (1996) Developmentally regulated neurite outgrowth response from dorsal root ganglion neurons to heparin-binding growth-associated molecule (HB-GAM) and the expression of HB-GAM in the targets of the developing dorsal root ganglion neurites. Eur J Neurosci 8:1658-1665.

Raulo E, Julkunen I, Merenmies J, Pihlaskari R, Rauvala H (1992) Secretion and biological activities of heparin-binding growth-associated molecule. Neurite outgrowth-promoting and mitogenic actions of the recombinant and tissue-derived protein. J Biol Chem 267:11408-11416.

Rauvala H (1989) An 18-kd heparin-binding protein of developing brain that is distinct from fibroblast growth factors. EMBO J 10:2933-2941

Rauvala H, Vankala A, Castren E, Nolo R, Raulo E, Merenmies J, Panule P (1994) Expression of HB-GAM (heparin-binding growth-associated molecule) in the pathways of developing axonal processes in vivo and neurite outgrowth in vitro induced by HB-GAM. Brain Res Dev Brain Res 79:167-176.

Relf M, Lejeune S, Scott PAE, Fox S, Smith K, Leek R, Moghaddam A, Whitehouse R, Bicknell R, Harris AL (1997) Expression of the angiogenic factors vascular endothelial cell growth factor, acidic and basic fibroblast growth factor, tumor growth factor beta-1, platelet-derived 
endothelial cell growth factor, placenta growth factor, and pleiotrophin in human primary breast cancer and its relation to angiogenesis. Cancer Res 57:963-969.

Robinson AP, White TM, Mason DW (1986) Macrophage heterogeneity in the rat as delineated by two monoclonal antibodies. MRC $\mathrm{OX}^{41}$ and $\mathrm{MRC} \mathrm{OX}{ }^{42}$ : the latter recognizing complement receptor type 3. Immunology 59:239-247.

Silos-Santiago I, Yeh HJ, Gurrieri MA, Guillerman RP, Li YS, Wolf J, Snider W, Deuel TF (1996) Localization of pleiotrophin and its mRNA in subpopulations of neurons and their corresponding axonal tracts suggests important roles in neural-glial interactions during development and in maturity. J Neurobiol 31:283-296.

Speliotes EK, Caday CG, Do T, Weise J, Kowall NW, Finklestein SP (1996) Increased expression of basic fibroblast growth factor (bFGF) following focal cerebral infarction in the rat. Mol Brain Res 39:31-41.

States BA, Honkaniemi J, Weinstein PR, Sharp FR (1996) DNA fragmentation and HSP70 protein induction in hippocampus and cortex occurs in separate neurons following permanent middle cerebral artery occlusions. J Cereb Blood Flow Metab 16:1165-1175.

Streit WJ (1990) An improved staining method for rat microglial cells using the lectin from Griffonia simplicifolia $\left(\mathrm{GSA}-\mathrm{IB}_{4}\right)$. J Histochem Cytochem 38:1683-1686.

Streit WJ, Kreutzberg GW (1987) Lectin binding by resting and reactive microglia. J Neurocytol 16:249-260.

Wanaka A, Carroll SL, Milbrandt J (1993) Developmentally regulated expression of pleiotrophin, a novel heparin binding growth factor, in the nervous system of the rat. Brain Res Dev Brain Res 72:133-144.

Yeh HJ, Ruit KG, Wang YX, Parks WC, Snider WD, Deuel TF (1991) PDGF A-chain gene is expressed by mammalian neurons during development and in maturity. Cell 64:209-216.

Yeh HJ, Silos-Santiago I, Wang YX, George RJ, Snider WD, Deuel TF (1993) Developmental expression of the platelet-derived growth factor $\alpha$-receptor gene in mammalian CNS. Proc Natl Acad Sci USA 90:19521956. 